$1-10-2014$

\title{
BSA-Boronic Acid Conjugate as Lectin Mimetics
}

\author{
Satya Nandana Narla \\ Cleveland State University \\ Poornima Pinnamaneni \\ Cleveland State University \\ Huan Nie \\ Harbin Institute of Technology \\ Yu Li \\ Harbin Institute of Technology \\ Xue-Long Sun \\ Cleveland State University, x.sun55@csuohio.edu
}

Follow this and additional works at: https://engagedscholarship.csuohio.edu/scichem_facpub

Part of the Biochemistry Commons, and the Chemistry Commons

How does access to this work benefit you? Let us know!

\section{Recommended Citation}

Narla, S. N.; Pinnamaneni, P.; Nie, H.; Li, Y.; Sun, X. BSA-boronic acid conjugate as lectin mimetics.

Biochem. Biophys. Res. Commun. 2014, 443, 562-567.

This Article is brought to you for free and open access by the Chemistry Department at EngagedScholarship@CSU.

It has been accepted for inclusion in Chemistry Faculty Publications by an authorized administrator of

EngagedScholarship@CSU. For more information, please contact library.es@csuohio.edu. 


\title{
BSA-boronic acid conjugate as lectin mimetics
}

\author{
Satya Nandana Narla ${ }^{a}$, Poornima Pinnamaneni ${ }^{a}$, Huan $\mathrm{Nie}^{\mathrm{b}}, \mathrm{Yu} \mathrm{Li}^{\mathrm{b}}$, Xue-Long Sun ${ }^{\mathrm{a}, *}$ \\ ${ }^{a}$ Department of Chemistry, Chemical and Biomedical Engineering, Center for Gene Regulation in Health and Disease (GRHD), Cleveland State University, \\ 2121 Euclid Avenue, Cleveland, $\mathrm{OH} 44115$, United States \\ ' School of Life Science and Technology, Harbin Institute of Technology, Harbin, Heilongiang, China
}

\section{A R T I C L E I N F O}

Article history:

Received 20 November 2013

Available online 8 December 2013

Keywords:

Boronic acid

Bovine serum albumin

Carbohydrate

Lectin

Alizarin Red S

Surface plasmon resonance

\begin{abstract}
A B S T R A C T
We report bovine serum albumin (BSA)-boronic acid (BA) conjugates as lectin mimetics and their glycocapturing capacity. The BSA-BA conjugates were synthesized by amidation of carboxylic acid groups in BSA with aminophenyl boronic acid in the presence of EDC, and were characterized by Alizarin Red $S$ (ARS) assay and SDS-PAGE gel. The BSA-BA conjugates were immobilized onto maleimide-functionalized silica beads and their sugar capturing capacity and specificity were confirmed by ARS displacement assay. Further, surface plasmon resonance (SPR) analysis of the glyco-capturing activity of the BSA-BA conjugates was conducted by immobilizing BSA-BA onto SPR gold chip. Overall, we demonstrated a BSA-BA-based lectin mimetics for glyco-capturing applications. These lectin mimetics are expected to provide an important tool for glycomics and biosensor research and applications.
\end{abstract}

(c) 2013 Elsevier Inc. All rights reserved.

\section{Introduction}

Carbohydrate recognition is a crucial event in many biological processes [1]. For example, cell surface carbohydrates, existing as glycoproteins [2], glycolipids [3], or proteoglycans [4], are involved in cell-cell signaling [5], immune recognition events [6], pathogen/ host interactions [7], tumor metastasis [8] as well as other cellular events. Therefore, carbohydrate recognition has come to the forefront of biological scientific research aiming to uncover the molecular mechanisms of many physiological and pathological processes and explore potential therapeutic targets or diagnostic mechanisms for various diseases, including viral infections, autoimmune diseases, cancer, and cardiovascular disorders [9]. In the past decade, lectins, the sugar-binding proteins, have been conventionally used to determine the structure and function of glycoproteins [10]. In particular, microarrays using panels of lectins on a single chip have been demonstrated as useful tools for glycomic analysis [11-15]. Though these lectin microarrays were claimed to be rapid and sensitive for glycomic study, the number of available lectins is still limited compared with diversity of glycan structures. In addition, some lectins can also be cross specific and binding multiple glycan structures and some even introduce some variability in their binding affinities dependent on their purification [16]. Therefore, exploring new lectins or lectin mimetics is highly demanded. Boronic acid (BA)-containing compounds have unique properties for carbohydrates since they form cyclic esters with diols of sugars in aqueous solution. BA conjugates have been employed as an artificial carbohydrate receptors [17!, membrane transport agents [18], cell surface carbohydrate recognition ligands [19], and as protective agents in synthesis of carbohydrates as well [20]. Most recently, boronic acid-containing macroligands such as nanoparticles [21-23], silica gel [24,25], magnetic beads [26], and polymers [27-35] etc. have been explored for glyco-capturing applications.

Bovine serum albumin (BSA) is a most abundant plasma protein and is very stable and soluble both in vitro and in vivo. It has been commonly used in laboratories for various biological assays. For example, BSA can be used to block nonspecific binding sites in many immunochemical experiments such as ELISA, immunoblotting and immunohistochemical studies. It is also widely used as carrier or supporter protein for vaccine and affinity ligand engineering. Herein, we envision that BSA-BA conjugate can be used as lectin mimetics for glycomic applications. First, the BSA-BA conjugates were synthesized by amidation of carboxylic acid groups in BSA with aminophenyl boronic acid. Then, BSA-BA conjugates were immobilized onto maleimide-functionalized silica beads and surface plasmon resonance (SPR) chip and their carbohydrate binding affinity and specificity were evaluated by column and SPR technique, respectively. The BSA-BA-based lectin mimetics are expected to provide an important tool for glycomics and biosensor research and applications (Fig. 1). 


\section{Materials and methods}

\subsection{Chemicals and reagents}

Bovine serum albumin (BSA), Aminophenylboronic acid, Alizarin Red S (ARS) and Sugars (Galactose, Glucose, Fructose, Fucose, Mannose, Lactose, Sialic acid, $N$-acetyl glucosamine) were purchased from Aldrich-Sigma Co. Bi-carbonate buffer ( $\mathrm{pH} \mathrm{8.3)} \mathrm{was}$ prepared using $0.1 \mathrm{M} \mathrm{NaHCO}_{3}$ and $0.5 \mathrm{M} \mathrm{NaCl}$, and then adjusted to $\mathrm{pH}$ 8.3. PBS buffer ( $\mathrm{pH} 7.4$ ) was prepared using $\mathrm{NaCl}, \mathrm{KCl}$, $\mathrm{Na}_{2} \mathrm{HPO}_{4}, \mathrm{KH}_{2} \mathrm{PO}_{4}$ and adjusted to $\mathrm{pH} 7.4$.

\subsection{Synthesis of BSA-boronic acid with conjugates}

BSA (100 mg, $1.5 \mu \mathrm{mol}$ ) and aminophenyl boronic acid (20 mg, $130 \mu \mathrm{mol})$ were dissolved in $5 \mathrm{~mL}$ of $0.05 \mathrm{M}$ MES buffer ( 2 - $(\mathrm{N}$-morpholino)ethane sulfonic acid) at $\mathrm{pH} 6.0$. To this mixture $10 \mathrm{mg}$ of EDC (1-ethyl-3-(3-dimethylaminopropyl) carbodiimide) $\mathrm{HCl}$ was added at constant stirring and was allowed to react for $2 \mathrm{~h}$ at room temperature and the $\mathrm{pH}$ was adjusted to 7.0 and left overnight at room temperature. The mixture was then subjected to Sephadex G-25 column for purification and lyophilized. BSA-BAs of different densities were prepared using same procedure as above by changing the ratios of BSA to BA.

\subsection{Immobilization of BSA-BA onto silica beads}

BSA-BA ( $45 \mathrm{mg}$ ) was dissolved in $3 \mathrm{~mL}$ of PBS ( $\mathrm{pH} 7.4$ ) buffer, to this mixture $250 \mathrm{mg}$ of maleimide-functionalized silica beads were added and reacted for $4 \mathrm{~h}$ at room temperature. This mixture was then subjected to centrifugation to remove the unreacted BSABA and washed 3 times for $10 \mathrm{~min}$ in PBS ( $\mathrm{pH} \mathrm{7.4)} \mathrm{buffer} \mathrm{and} \mathrm{dried}$ overnight under vacuum. Same procedure was followed for the immobilization of BSA-BA2 and BSA-BA3 onto maleimide functionalized silica beads.

\subsection{Characterization of $B S A-B A$ on silica beads}

BSA-BA modified silica beads (15 $\mathrm{mg}$ ) were incubated with ARS $\left(4 \times 10^{-4} \mathrm{M}\right)$ in PBS ( $\left.\mathrm{pH} 7.4\right)$ buffer for about $30 \mathrm{~min}$ and centrifuged to remove the unreacted ARS solution. These beads were washed for 3 times with PBS ( $\mathrm{pH} 7.4$ ) buffer to remove any unreacted or loosely bound ARS. $1 \mathrm{~mL}$ of $0.1 \mathrm{M}$ fructose sugar in PBS $(\mathrm{pH} 7.4)$ buffer was added and incubated for $30 \mathrm{~min}$. Displaced
ARS solution was removed by centrifugation and subjected to fluorescence spectroscopy.

\subsection{Quantification of $B S A-B A$ on silica beads}

Different concentrations of ARS solutions were prepared and subjected to UV-vis spectroscopy to obtain a calibration curve. To BSA-BA1, BSA-BA2 and BSA-BA3 modified silica beads $(15 \mathrm{mg}) 0.5 \mathrm{ml}$ of ARS $\left(4 \times 10^{-4} \mathrm{M}\right)$ solution was added and reacted for $30 \mathrm{~min}$. The mixture was centrifuged and supernatant liquid was subjected to UV-vis spectroscopy to quantify the amount of BSA-BA immobilized onto silica beads.

\subsection{Sugar binding specificity to $B S A-B A-S B$ at $p H 7.4$ and $p H 8.3$}

Maleimide functionalized silica beads, BSA modified Silica beads, and BSA-BA modified silica beads $(15 \mathrm{mg}$ ) were incubated with ARS solution $\left(4 \times 10^{-4} \mathrm{M}\right)$ for $30 \mathrm{~min}$ and centrifuged to remove the unreacted ARS solution. Silica beads were washed 3 times with PBS ( $\mathrm{pH} 7.4$ ) to remove any unreacted or loosely bound ARS followed by incubation of these silica beads with sugar solutions (Lactose, Fructose, Fucose, Glucose, Galactose, Mannose, Sialic acid, $N$-acetyl glucosamine) in PBS (pH 7.4) (0.1 M, $1 \mathrm{~mL}$ ) and $\mathrm{NaHCO}_{3}$ (pH 8.3) buffer $(0.1 \mathrm{M}, 1 \mathrm{~mL}$ ) for 30 min, respectively. Displaced ARS solutions were removed by centrifugation and subjected to fluorescence spectroscopy.

\subsection{Sugar binding specificity to $B S A-B A$ by SPR}

The specific binding of sugars to immobilized BSA-BA was analyzed with SPR with a BI 2000 biosensor system (BI Biosensing Instruments). To prepare the sensing surface, the commercial SPR gold chip (BI Biosensing Instruments) was rinsed with piranha solution of sulfuric acid and hydrogen peroxide $(1: 1, v / v)$, followed by water and ethanol ( 3 times) and dried under nitrogen. BSA-BA3 was covalently immobilized onto gold chip surface by flowing the BSA-BA3 solution $(0.375 \mathrm{mg} / \mathrm{mL}$, PBS ( $\mathrm{pH} 7.0)$ buffer) at a flow rate of $7 \mu \mathrm{L} / \mathrm{min}$ for $600 \mathrm{~s}$.

Then, a series of sugar solutions (Lactose, Fructose, Fucose, Glucose, Galactose, Mannose, Sialic acid, $N$-acetyl glucosamine, $0.1 \mathrm{nM}$ ) in PBS running buffer ( $\mathrm{pH} 7.4$ ) were injected over the immobilized BSA-BA3 at a flow rate of $15 \mu \mathrm{L} / \mathrm{min}$ for $200 \mathrm{~s}$. The association and dissociation constants of the sugar binding to immobilized BSA-BA3 were determined by standard BI 2000

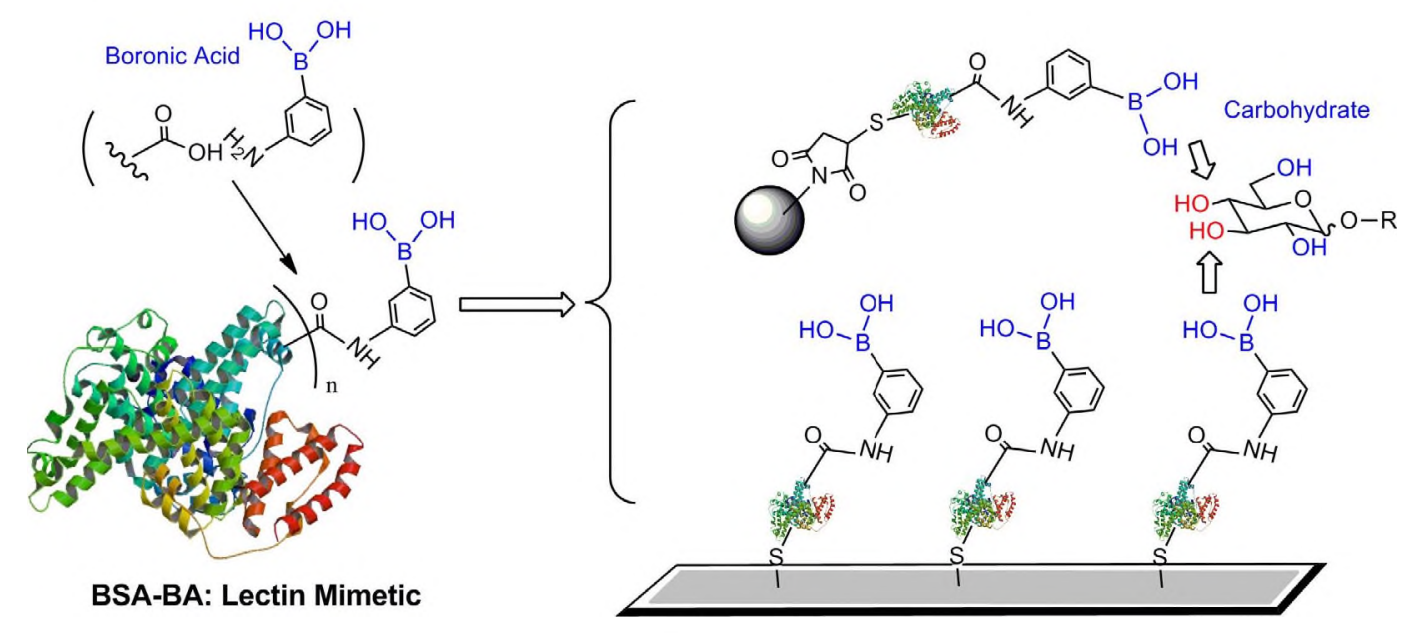

Fig. 1. BSA-boronic acid (BA) conjugate as lectin mimetics and its immobilization onto silica gel beads and SPR chip for glycomics and biosensor applications. 
(scrubber) evaluation software. For studying the sugar binding at $\mathrm{NaHCO}_{3}$ ( $\mathrm{pH} 8.3$ ) buffer same procedure was followed as above.

\section{Results and discussion}

3.1. Synthesis and characterization of bovine serum albumin (BSA) boronic acid conjugates (BSA-BA)

The BSA-BA conjugates were synthesized by amidation of carboxylic acid groups in BSA with aminophenyl boronic acid in the presence of EDC in MES buffer at $\mathrm{pH} 7.0$ overnight, followed by purification on Sephadex G-25 column. Different densities of BSA-BA were synthesized by altering the ratio of APBA to BSA (Table 1). The resultant BSA-BA conjugates were characterized by Alizarin Red S (ARS) assay and SDS-PAGE gel. When ARS binds to boronic acid a dramatic change in color, UV, and fluorescence intensity was observed, thus, it has been used extensively to quantify the boronic acid and also to determine the carbohydrate binding affinity to boronic acid ligands [36-38]. Briefly, ARS shows a color change from pink to yellow when bound to BSA-BA and shifts the UV absorption wavelength from around 510 to $460 \mathrm{~nm}$ in PBS ( $\mathrm{pH} 7.4$ ) buffer. When adding high concentration ( $1 \mathrm{M}$ ) of fructose, the fructose-boronic acid complex forms and releases ARS with the color changing from yellow to pink and the wavelength shifting back to $510 \mathrm{~nm}$ (Fig. 2A). Further, the BSA-BA conjugates were characterized by SDS-PAGE (Fig. 2B), where the BSA-BA conjugates was observed with increase in molecular weight. Three BSA-BA conjugates of different BA densities were synthesized and quantified by ARS assay monitored through fluorescent spectroscopy (Table 1). As a result, a linear increase in the conjugation of boronic acid to BSA was observed with the BA/BSA ratio increase in the reactions.

Silica gel has been widely used as small, rigid particles for high performance affinity chromatography as it is capable of withstanding high flow rates and/or pressures. Recently, surface functionalization of silica gel has received vast attentions for affinity chromatography applications [27,39]. In the present study, BSABA conjugate was immobilized onto silica gel and its carbohydrate binding affinity and specificity was investigated. First, BSA-BA was dissolved in PBS (7.4 pH) buffer and added to commercially available maleimide functionalized silica beads (Sigma), allowed to

Table 1

Quantification of BSA-BA conjugates based on ARS assay.

\begin{tabular}{lll}
\hline Protein-BA & Reaction: APBA/Protein (mol) & Product: BA/Protein (mol) \\
\hline BSA-BA1 & $21 / 1$ & $9 / 1$ \\
BSA-BA2 & $32 / 1$ & $17 / 1$ \\
BSA-BA3 & $42 / 1$ & $26 / 1$ \\
\hline
\end{tabular}

react for $4 \mathrm{~h}$, followed the un-reacted BSA-BA was removed by washing the silica beads with PBS ( $\mathrm{pH} 7.4$ ) buffer 3 times to afford the BSA-BA functionalized silica gel beads (SB-BSA-BA). The resultant $\mathrm{SB}-\mathrm{BSA}-\mathrm{BA}$ was characterized by IR spectroscopy by comparing with BSA modified silica beads and un-treated maleimide functionalized silica beads, respectively. In particular strong amide bond absorptions $\left(1600 \mathrm{~cm}^{-1}\right)$ were observed for both BSA-BA and BSA modified silica beads, while strong hydroxyl group absorptions $\left(3700 \mathrm{~cm}^{-1}\right.$ ) were observed for BSA-BA modified silica beads by comparing to un-treated maleimide functionalized silica beads (Supporting Information Fig. S1).

The carbohydrate binding affinity and specificity of the SB-BSA-BA was confirmed by ARS displacement assay. First, SB-BSA-BA (15 mg) was incubated with ARS $(0.1 \mu \mathrm{M})$ in PBS ( $\mathrm{pH} 7.4)$ buffer at room temperature for $30 \mathrm{~min}$, then the unreacted ARS was removed by pipetting the supernatant out and washing the silica beads with PBS ( $\mathrm{pH} 7.4$ ) buffer 3 times. As a result, SB-BSA-BA incubated with ARS solution showed strong ARS binding compared to unmodified silica gel beads and BSA modified silica beads incubated with the same ARS solution (Fig. 3A1-5). Among the BSA-BA conjugates used, the BSA-BA3 modified silica beads displayed highest binding of ARS as it has higher density of BA compared to BSA-BA2 and BSA-BA1, respectively (Table 1). Further, the ARS bound SB-BSA-BA was incubated with fructose $(1 \mathrm{M})$ in PBS ( $\mathrm{pH} 7.4$ ) buffer at room temperature for $30 \mathrm{~min}$ to displace the bound ARS from the SB-BSA-BA. The displaced ARS was subjected to fluorescent spectroscopy. Again, solution from the BSA-BA3 modified silica beads showed the highest fluorescent intensity (Fig. 3D3) compared to BSA-BA2 and BSA-BA1 modified silica beads (Fig. 3D4 and D5), while BSA modified silica beads and silica gel beads alone showed no ARS released (Fig. 3D1 and D2). All these data indicated that SB-BSA-BA has BA-densitydependent carbohydrate binding capacity.

Different sugars have special binding specificities to boronic acid and it is highly $\mathrm{pH}$ dependent. In the present study, we investigated the specificity of eight common carbohydrates to BSA-BA3 modified silica gel under two different $\mathrm{pH}$ conditions, 7.4 and 8.3 by ARS displacement assay, respectively. Briefly, BSA-BA3 modified silica beads, BSA modified silica beads and maleimide functionalized silica beads were incubated with ARS solution (0.1 mM PBS ( $\mathrm{pH} \mathrm{7.4)} \mathrm{buffer)} \mathrm{for} 30 \mathrm{~min}$ at room temperature, then centrifuged and the unreacted ARS was removed by washing the silica beads with PBS (pH 7.4) buffer. Next, sugar solutions (Lactose, Fructose, Fucose, Glucose, Galactose, Mannose, Sialic acid, $N$-acetyl glucosamine, $0.1 \mathrm{mM}$ ) in PBS ( $\mathrm{pH} 7.4$ ) buffer and $\mathrm{NaHCO}_{3}(\mathrm{pH} \mathrm{8.3)} \mathrm{buffer}$ were added and incubated for $30 \mathrm{~min}$, respectively. ARS displaced by each sugar was subjected to fluorescence spectroscopy. As a result, at $\mathrm{pH} 7.4$, the binding specificities were shown from


Fig. 2. Characterization of BSA-BA: (A) Alizarin Red S assay and (B) SDS-PAGE (M. Marker, 1. BSA, 2. BSA-BA). 

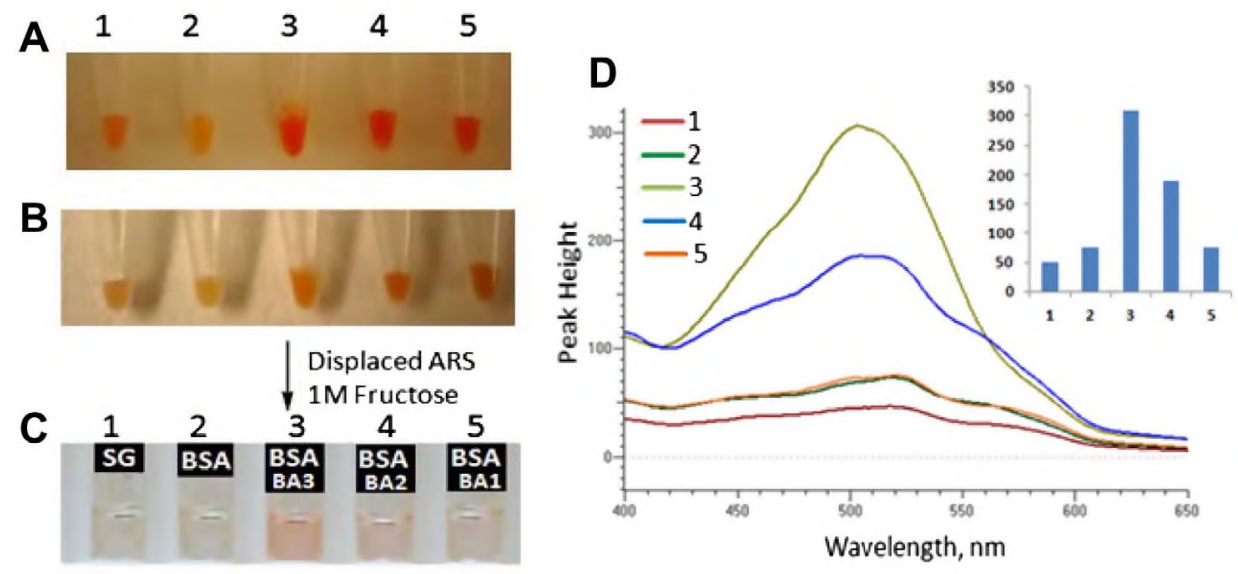

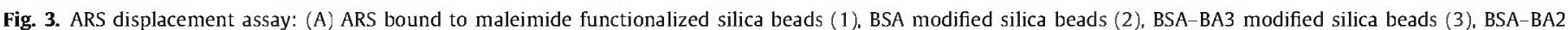

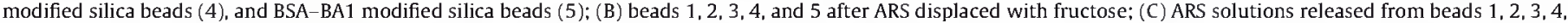

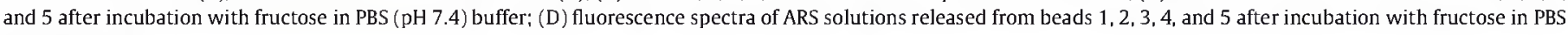
(pH 7.4) buffer.

A

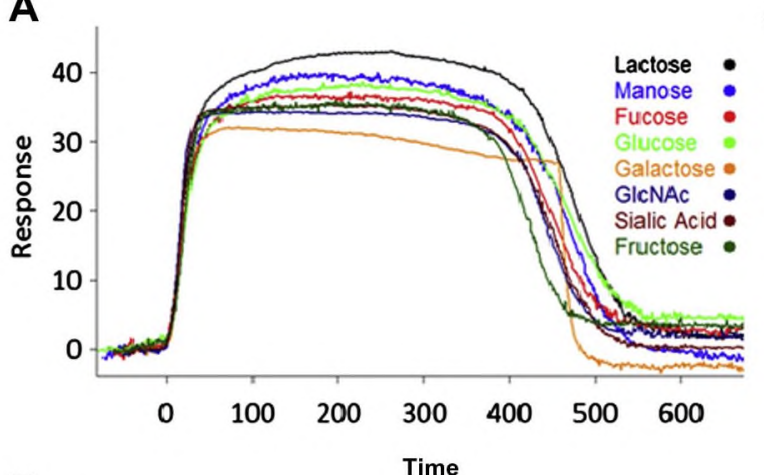

B

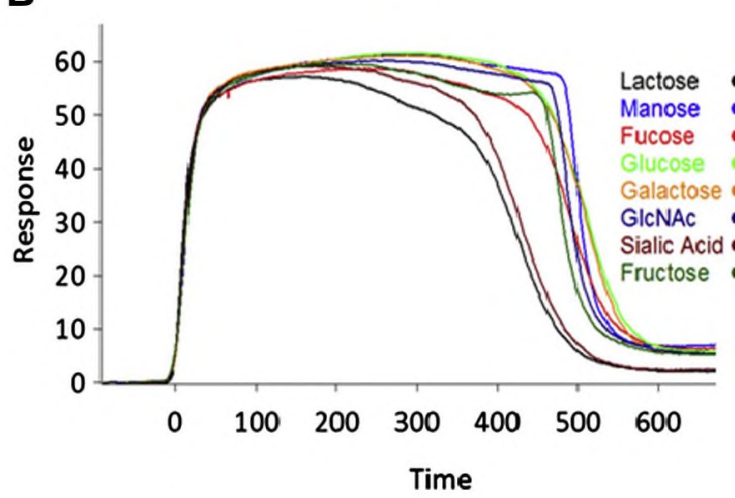

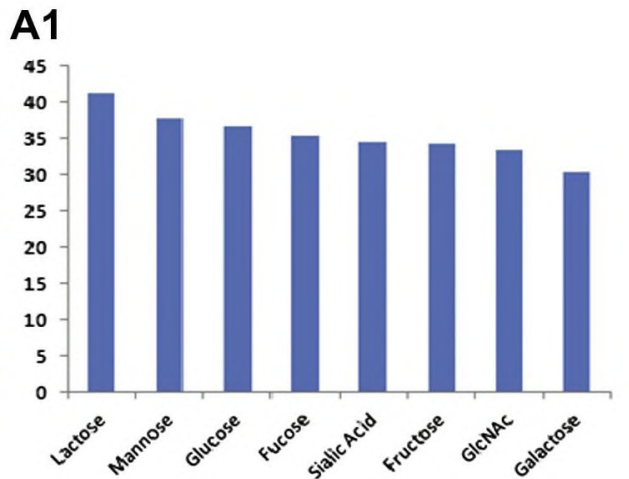

B1

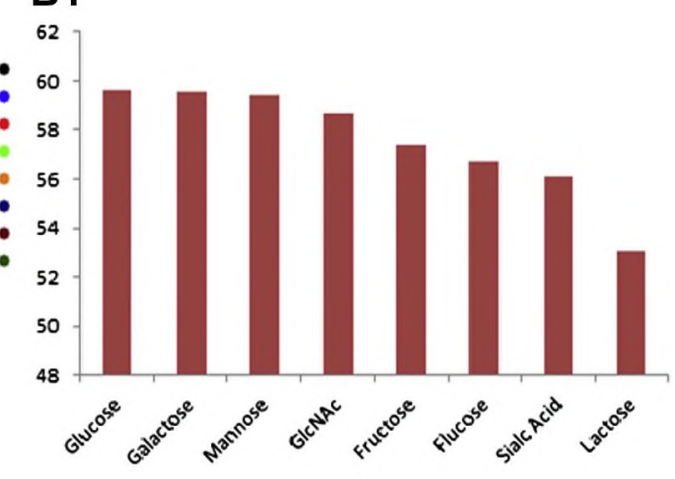

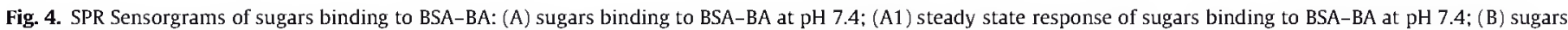
binding to BSA-BA at $\mathrm{pH} 8.3$; (B1) steady state response of sugars binding to BSA-BA at $\mathrm{pH} 8.3$.

highest to lowest as Fructose $>$ Galactose $>$ Mannose $>$ Fucose $>$ Lactose $>$ Sialic Acid $>$ GlcNAC $>$ Glucose, while $\mathrm{pH}$ at 8.3 , was Fructose $>$ Fucose $>$ Lactose $>$ Galactose $>$ Mannose $>$ GlcNAc $>$ Sialic Acid $>$ Glucose (Supporting Information Fig. S2). Also, the sugar binding capacity are higher at $\mathrm{pH} 8.3$ than at 7.4 as the all fluorescent intensities of ARS released by all sugars at $\mathrm{pH} 8.3$ are higher than that in $\mathrm{pH} 7.4$ (Supporting Information Fig. S2).

\subsection{Determination of sugar binding specificity of BSA-BA by surface plasmon resonance (SPR)}

For further confirmation of sugar binding to BSA-BA, SPR technique was employed. BSA-BA3 was immobilized on the gold chip via Au - thiol coupling in PBS ( $\mathrm{pH} 7.4$ ) buffer for $10 \mathrm{~min}$ at flow rate $7 \mu \mathrm{L} / \mathrm{min}$. Followed by injecting the sugar solutions $(0.1 \mu \mathrm{M})$ at flow rate of $15 \mu \mathrm{L} / \mathrm{min}$ for $3 \mathrm{~min}$ in PBS ( $\mathrm{pH} 7.4$ ) buffer (Fig. $4 \mathrm{~A}$ ). The same SPR experiment was performed by using $\mathrm{NaHCO}_{3}(\mathrm{pH}$ 8.3) buffer for studying sugar binding specificities (Fig. 4B). All the sugars exhibited approximately similar binding response between $30 \mathrm{RU}$ and $40 \mathrm{RU}$ at $\mathrm{pH} 7.4$ (Fig. $4 \mathrm{~A}$ ), while the binding response of all the sugars increased to around $60 \mathrm{RU}$ at $\mathrm{pH} 8.3$ (Fig. 4B). Interestingly, the binding specificities of all sugars were different from that in the ARS assay. However, the binding capacity of the sugars was higher at $\mathrm{pH} 8.3$ than that in $\mathrm{pH} 7.4$, which was the same as observed in ARS assay. Further, the association constant of almost all sugars was observed to be higher at $\mathrm{pH} 8.3$ than 
Table 2

Binding kinetics of sugars to immobilized BSA-BA in SPR assays.

\begin{tabular}{|c|c|c|c|c|c|c|}
\hline & \multicolumn{3}{|l|}{$7.4 \mathrm{pH}$} & \multicolumn{3}{|l|}{$8.3 \mathrm{pH}$} \\
\hline & $K_{\mathrm{a}}\left(\mathrm{M}^{-1} \mathrm{~s}^{-1}\right)$ & $K_{\mathrm{d}}\left(\mathrm{s}^{-1}\right)$ & $K_{\mathrm{D}}(\mathrm{M})$ & $K_{\mathrm{a}}\left(\mathrm{M}^{-1} \mathrm{~s}^{-1}\right)$ & $K_{\mathrm{d}}\left(\mathrm{s}^{-1}\right)$ & $K_{\mathrm{D}}(\mathrm{M})$ \\
\hline Lactose & $2.22 \times 10^{5}$ & $8.91 \times 10^{-3}$ & $40.07 \times 10^{-8}$ & $6.27 \times 10^{5}$ & $1.65 \times 10^{-2}$ & $26.37 \times 10^{-8}$ \\
\hline Mannose & $2.09 \times 10^{5}$ & $1.11 \times 10^{-2}$ & $53.29 \times 10^{-8}$ & $3.81 \times 10^{5}$ & $5.63 \times 10^{-3}$ & $14.78 \times 10^{-8}$ \\
\hline Fucose & $2.63 \times 10^{5}$ & $1.06 \times 10^{-2}$ & $40.40 \times 10^{-8}$ & $4.48 \times 10^{5}$ & $6.71 \times 10^{-3}$ & $14.99 \times 10^{-8}$ \\
\hline Glucose & $2.27 \times 10^{5}$ & $8.34 \times 10^{-3}$ & $36.74 \times 10^{-8}$ & $3.62 \times 10^{5}$ & $6.11 \times 10^{-3}$ & $16.88 \times 10^{-8}$ \\
\hline Galactose & $3.25 \times 10^{5}$ & $1.29 \times 10^{-2}$ & $39.73 \times 10^{-8}$ & $3.78 \times 10^{5}$ & $6.30 \times 10^{-3}$ & $16.66 \times 10^{-8}$ \\
\hline GlcNAc & $4.33 \times 10^{5}$ & $1.21 \times 10^{-2}$ & $28.10 \times 10^{-8}$ & $4.07 \times 10^{5}$ & $6.75 \times 10^{-3}$ & $16.57 \times 10^{-8}$ \\
\hline Sialic acid & $3.79 \times 10^{5}$ & $1.28 \times 10^{-2}$ & $33.85 \times 10^{-8}$ & $4.75 \times 10^{5}$ & $1.44 \times 10^{-2}$ & $30.41 \times 10^{-8}$ \\
\hline Fructose & $3.87 \times 10^{5}$ & $1.85 \times 10^{-2}$ & $47.87 \times 10^{-8}$ & $4.05 \times 10^{5}$ & $7.52 \times 10^{-3}$ & $18.56 \times 10^{-8}$ \\
\hline
\end{tabular}

at $\mathrm{pH} 7.4$ and the dissociation of all sugars except lactose was observed to be almost 2-fold lower at $\mathrm{pH} 8.3$ than at $\mathrm{pH} 7.4$ (Table 2) indicating that the sugar bindings are much stronger at $\mathrm{pH} 8.3$ than at $\mathrm{pH} 7.4$

\section{Conclusion}

In this work, we demonstrated a BSA-boronic acid conjugate as lectin mimetics. The conjugates were synthesized by conjugation of amino phenyl boronic acid to bovine serum albumin (BSA). The boronic acid conjugated proteins were immobilized onto commercially available maleimide functionalized silica gel via thiolmaleimide coupling and on the gold chip via thiol-thiol coupling, which were used to study the sugar binding specificity of several sugars by ARS displacement assay and SPR, respectively. The binding specificity and capacity of different carbohydrates to immobilized BSA-BA were investigated at different $\mathrm{pH}$ conditions, proving that the carbohydrate specificity and capacity to the boronic acid are $\mathrm{pH}$ dependent. These lectin mimetics will provide an important tool for future glycomics and biosensor research and applications.

\section{Acknowledgments}

The authors acknowledge the Ohio Department of Development (ODOD) for supporting this research through research fund at the Center for Gene Regulation in Health and Disease (GRHD) at Cleveland State University. This work was supported in part by Grants from National Science Foundation MRI Grant (CHE-1126384). This work was partially supported by Grants from The National Natural Science Foundation of China (31328006).

\section{Appendix A. Supplementary data}

Supplementary data associated with this article can be found, in the online version, at http://dx.doi.org/10.1016/j.bbrc.2013.12.006.

\section{References}

[1] B. Wang, G.]. Boons (Eds.), Carbohydrate Recognition: Biological Problems, Methods and Applications, Wiley, 2011

[2] M. Nakano, K. Kakehi, M.H. Tsai, Y.C. Lee, Detailed structural features of glycan chains derived from $\alpha 1$-acid glycoproteins of several different animals: the presence of hypersialylated, 0 -acetylated sialic acids but not disialyl residues, Glycobiology 14 (2004) 431-441.

[3] C.A. Bush, M. Martin-Pastor, A. Imberty, Structure and conformation of complex carbohydrates of glycoproteins, glycolipids, and bacterial polysaccharides, Ann. Rev. Biophys. Biomol. Struct. 28 (1999) 269-275.

[4] P.M. Berninsone, C.B. Hirschberg, The nematode Caenorhabditis elegans as a model to study the roles of proteoglycans, Glycoconjugate J. 19 (2002) 325 330.

[5] S.L. Flistsch, R.V. Ulijn, Sugars tied to the spot, Nature 421 (2003) 219-220.

[6] J.M. Sodetz, J.C. Paulson, P.A. McKee, Carbohydrate composition and identification of blood group $\mathrm{A}, \mathrm{B}$, and $\mathrm{H}$ oligosaccharide structures on human Factor VIII/von Willebrand factor, J. Biol. Chem. 254 (1979) 1075410760.

[7] K.A. Karlsson, Microbial recognition of target-cell glycoconjugates, Curr. Opir Struct. Biol. 5 (1995) 622-635.

[8] K.]. Lee, S. Mao, C. Sun, C. Gao, O. Blixt, S. Arrues, L.G. Hom, G.F. Kaufmann, T.Z Hoffman, A.R. Coyle, J. Paulson, B. Felding-Habermann, K.D. Janda, Phagedisplay selection of a human single-chain fv antibody highly specific for melanoma and breast cancer cells using a chemoenzymatically synthesized G(M3)-carbohydrate antigen, J. Am. Chem. Soc. 124 (2002) 12439-12446.

[9] E.D. McGowan, K. Bowman, Background Paper on Glycosciences and Glycomics in the United States. Board on Chemical Sciences and Technology and Board on Life Sciences, National Research Council, 2010.

[10] H. Rudiger, H.J. Gabius, Plant lectins: occurrence, biochemistry, functions and applications, Glycoconjugate J. 18 (2001) 589-613.

[11] K.T. Pilobello, L. Krishnamoorthy, D. Slawek, L.K. Mahal, Development of a lectin microarray for the rapid analysis of protein glycopatterns, ChemBioChem 6 (2005) 985-989.

[12] S. Angeloni, J.L. Ridet, N. Kusy, H. Gao, F. Crevoisier, S. Guinchard, S. Kochhar, H. Sigrist, N. Sprenger, Glycoprofiling with micro-arrays of glycoconjugates and lectins, Glycobiology 15 (2005) 31-41.

[13] T. Zheng, D. Peelen, L.M. Smith, Lectin arrays for profiling cell surface carbohydrate expression, J. Am. Chem. Soc. 127 (2005) 9982-9983.

[14] A. Kuno, N. Uchiyama, S. Koseki-Kuno, Y. Ebe, S. Takashima, M. Yamada, J Hirabayashi, Evanescent-field fluorescence-assisted lectin microarray: a new strategy for glycan profiling, Nat. Methods 2 (2005) 851-856.

[15] K.L. Hsu, K.T. Pilobello, L.K. Mahal, Analyzing the dynamic bacterial glycome with a lectin microarray approach, Nat. Chem. Biol. 2 (2006) 153-157.

[16] T.D. James, S. Shinkai, Artificial receptors as chemosensors for carbohydrates, Top. Curr. Chem. 218 (2002) 159-200.

[17] H. Fang, G. Kaur, B. Wang, Progress in boronic acid-based fluorescent glucose sensors, J. Fluorescence 14 (2004) 481-489.

[18] P.J. Duggan, Fructose-permeable liquid membranes containing boronic acid carriers, Aust. J. Chem. 57 (2004) 291-299.

[19] J. Yan, H. Fang, B. Wang, Boronolectins and fluorescent boronolectins: an examination of the detailed chemistry issues important for the design, Med. Res. Rev. 25 (2005) 490-520.

[20] P.J. Duggan, E.M. Tyndall, Boron acids as protective agents and catalysts in synthesis, J. Chem. Soc. Perkin Trans. 111 (2002) 1325-1339.

[21] F. Frank, G. Kjersti, H. Dag-Eric, S. Erling, Protein-boronic acid conjugates and their binding to low-molecular-mass cis-diols and glycated hemoglobin, J Chromatogr., B. 670 (1995) 37-45.

[22] J.C. Manimala, T.A. Roach, Z. Li, J.C. Gildersleeve, High-throughput carbohydrate microarray analysis of 24 lectins, Angew. Chem., Int. Ed. Eng]. 45 (2006) 3607-3610.

[23] J. Zhang, C.D. Geddes, J.R. Lakowciz, Complexation of polysaccharide and monosaccharide with thiolate boronic acid capped on silver nanoparticle. Anal. Biochem. 332 (2004) 253-260.

[24] C. Cannizzo, S. Amigoni-Gerbier, C. Larpent, Boronic acid-functionalized nanoparticles: synthesis by microemulsion polymerization and application as a re-usable optical nanosensor for carbohydrates, Polymer 46 (2005) 1269 1276.

[25] L. Zhang, Y. Xu, H. Yao, L. Zie, J. Yao, H. Lu, P. Yang, Boronic acid functionalized core-satellite composite nanoparticles for advanced emichment of glycopeptides and glycoproteins, Chem. Eur. J. 15 (2009) 10158-10166.

[26] Y. Xu, Z. Wu, L. Zhang, H. Lu, P. Yang, P.A. Webley, D. Zhao, Highly specific enrichment of glycopeptides using boronic acid-functionalized mesoporous silica, Anal. Chem. 81 (2009) 503-508.

[27] A.E. Ivanov, H.A. Panahi, M.V. Kuzimenkova, L. Nisson, B. Bergenstahl, H.S. Waqif, M. Jahanshahi, I.Y. Galaev, B. Mattiasson, Affinity adhesion of carbohydrate particles and yeast cells to boronate-containing polymer brushes grafted onto siliceous supports, Chem. Eur. J. 12 (2006) 7204-7214.

[28] P.]. Duggan, D.A. Offermann, Remarkably selective saccharide recognition by solid-supported peptide boronic acids, Tetrahedron 65 (2009) 109-114.

[29] D. Qi, H. Zhang, J. Tang, C. Deng, X. Zhang, Facile synthesis of mercaptophenylboronic acid-functionalized core-shell structure 
$\mathrm{Fe}_{3} \mathrm{O}_{4} @ \mathrm{C} @ A u$ magnetic microspheres for selective enrichment of glycopeptides and glycoproteins, J. Phys. Chem. C. 144 (2010) 9221-9226.

[30] J.N. Cambre, D. Roy, S.R. Gondi, B.S. Sumerlin, Facile strategy to well-defined water-soluble boronic acid (co)polymers. J. Am. Chem. Soc. 129 (2007) 10348 10349.

[31] D. Roy, ].N. Cambre, B.S. Sumerlin, Sugar-responsive block copolymers by direct RAFT polymerization of unprotected boronic acid monomers, Chem. Commun. (2008) 2477-2479.

[32] D. Roy, J.N. Cambre, B.S. Sumerlin, Triply-responsive boronic acid block copolymers: solution self-assembly induced by changes in temperature, $\mathrm{pH}$, or sugar concentration, Chem. Commun. (2009) 2106-2108.

[33] S. Chalagalla, X-L Sun, Synthesis and characterization of biotin chain-end functionalized boronic acid-containing polymer (boropolymer) as functional glyco-affinity macroligand, React. Funct. Polym. 70 (2010) 471-476.

[34] S. Chalagalla, Y. Wang, D. Ray, X. Zeng, X.-L. Sun, Synthesis and characterization of oriented glyco-capturing macroligand, ChemBioChem 11 (2010) 2018-2025.
[35] Y. Wang, S. Chalagalla, T. Li, X.-L. Sun, W. Zhao, P. Wang, X. Zeng, Multivalent interaction-based carbohydrate biosensors for signal amplification, Biosens. Bioelectron. 26 (2010) 996-1001.

[36] B. Wang, S. Greg, Alizarin Red S as a general optical reporter for studying the binding of boronic acids with carbohydrates, Chem. Commun. (2001) 1608 1609.

[37] Y. Kubo, T. Ishida, A. Kobayashi, T.D. James, Fluorescent alizarin-phenylboronic acid ensembles: design of self-organized molecular sensors for metal ions and anions, ]. Mater. Chem. 15 (2005) 2889-2895.

[38] S. Thomas, M. Michael, A color sensor for catecholamines, Angew. Chem. 117 (2005) 2305-2310.

[39] L. Liu, Y Zhang, L. Zhang, G. Yan, J. Yao, P. Yang, H. Lu, Highly s pecific revelation of rat serum glycopeptidome by boronic acid-functionalized mesoporous silica, Anal. Chim. Acta 753 (2012) 64-72. 